\title{
Invasive Prenatal Diagnosis
}

\author{
Sonja Pop-Trajković1, Vladimir Antić ${ }^{1}$ and Vesna Kopitović \\ ${ }^{1}$ Clinic for Gynecology and Obstetrics, Clinical center of Niš \\ ${ }^{2}$ Clinic for Gynecology and Obstetrics, Clinical Center of Vojvodina \\ Serbia
}

\section{Introduction}

Prenatal diagnosis, traditionally used as a synonymous for invasive fetal testing and evaluation of chromosomal constellation, presently encompasses many other issues like pedigree analyses, fetal risk assessment, population screening, genetic counseling and fetal diagnostic testing as well. Ultrasound guided chorionic villus samling (CVS), amniocentesis and, to a lesser extent, fetal blood sampling are used routinely in fetal medicine units. Other fetal tissue biopsies such as skin, liver and muscle biopsy are used only rarely. In this chapter we discuss the invasive diagnostic procedures in maternal fetal medicine with specific interest of showing the list of indications basic principles used for choosing the particular invasive technique, linkage of non invasive with invasive diagnostic procedures, precise description of techniques, list of complications and their prevention and management, all of these based on the recent scientific results and clinical experiences publicized in the available literature.

\section{Chorionic villus sampling}

The ability to sample and analyse villus tissue was demonstrated in China, in 1975 (Department of Obstetrics and Gynecology THoAIaSCA, 1975). Trying to develop a technique for fetal sex determination, Chinese inserted a thin catheter into the uterus guided only by the tactile sensation and small pieces of villi were aspirated. By today's standards of ultrasonically guided invasive procedures this approach seems crude, but their diagnostic accuracy and low miscarriage rate demonstrated the feasibility of first-trimester sampling. Major advancements have occurred since that time in instrumentation, techniques for direct kariotyping, faster culturing of cells and in the molecular and biochemical assay of chorionic villi. Today in experienced centers, chorionic villus sampling (CVS) as a method of obtaining chorionic villi using transcervical or transabdominal approach, can be utilized as a primary prenatal diagnostic tool. Although CVS has the advantage of being carried out very early in pregnancy to the widespread amniocentesis, due to, more likely, the more technically demanding aspects of sampling, CVS has still not replaced amniocentesis in many centers.

\subsection{Timing and technique}

CVS is usually performed between 10 and 12 weeks of pregnancy. The risk and severity of limb deficiency appear to be associated with the timing of CVS: the risk before the end of 10 
weeks gestation is higher than the risk from CVS done before that time. The upper limit for transcervical sampling has been suggested to be 12-13 weeks. Indeed, by the end of the first trimester, the gestational sac becomes attached to the decidual wall. Thereafter, any attempt to insert either a catheter or a biopsy forceps entails a higher risk of indenting and damaging the membranes.There are two paths for approaching placenta: through the maternal abdomen using a needle or through the cervical canal by catheter or biopsy forceps. For transcervical CVS, after ultrasound examination and determination of placental location, position of uterus and cervix is determined and a catheter path is mapped. (Vaughan \& Rodeck,2001). The distal 3 to $5 \mathrm{~cm}$ of the sampling catheter is molded into a slightly curved shape and the catheter gently passed under ultrasound guidance through the cervix to the distal edge of the placenta under the ulatrasound visualization. The stylet is removed and a syringe with nutrient medium is attached. After obtaining negative pressure by a syringe the catheter is gently removed. In most cases chorionic villi are seen with naked eye in the syring (Dadelszen et al.,2005). For transabdominal approach the skin surface is treated with antiseptic solution. Trajectory of the needle should be chosen as much as parallel to the long axis of the trophoblast. The 20-gauge needle is inserted into chorionic villi (single needle technique). In some centers double needle technique is used. With this technique, 18-gauge needle is inserted into chorionic villi and the stylet is removed, then a smaller, 20-gauge needle with the aspirating syringe is inserted through this needle. Therefore if the sample is not adequate, sampling procedure with this smaller needle through 18-gauge needle can be repeated as necessary. Each technique (single or double needle) can be either free-hand or with needle-guide (alfirevic et al.,2003).

\subsection{Counseling before CVS}

Individualized counseling, by the obstetrician or an expert in genetics should always precede the procedure and support the couple in coming to a decision. Adequate time and personnel should be available to conduct a high-quality informed consent process in order to enhance the woman's decision making about prenatal testing. Counseling patients before CVS should emphasize some issues. First, the indication for invasive diagnosis in general and for CVS in particular. CVS is recommended for patients with very high risk of single gene disorder or chromosomal translocations in offspring. Although CVS should be also available to lower risk patients who wish karyotyping, the amniocentesis as an alternative should be offered. Second, specific data should be given to parents about failure, falsenegative and false-positive results of the procedure and the need of amniocentesis in cases with confined placental mosaicism which occurs in approximately $1-2 \%$. At the end, the risks of CVS should be discussed, especially the risk of fetal loss. The risk of other complications is low and should not be discussed routinely, unless the patient asks. Written material about CVS might also be given to the couple. It is good clinical practice to obtain formal written consent for CVS before the procedure and it is mandatory in most centers.

\subsection{Indications}

Prenatal diagnosis in the first trimester has advantages over midtrimester diagnosis for a number of reasons. The first one is the advantage of an earlier procedure which brings relief to the patient when the results are normal and on the other hand allows an easier and more private pregnancy termination when necessary. Earliest time for having the chromosome 
results is the $14^{\text {th }}$ week with CVS and the $19^{\text {th }}$ week with amniocentesis. First trimester abortion is followed by significantly lower rate of clinical complications. Speaking of emotional effect on patient, it is less stressful than labor induction and delivery at about 20 weeks. Also, by that time maternal-fetal bonding is not clearly established and the pregnancy is generally not visible to the environment. Additionally, early diagnosis is essential when there is a need for in utero gene or stem cell therapy for the correction a genetic defect. The earliest applications of CVS were fetal sex determination and prenatal diagnosis of hemoglobinonopathies by DNA analysis ( Monni et al.,1993) Since then, advances in cytogenetic and DNA analysis techniques have remarkably expanded the number and types of genetic conditions detectable in the prenatal period. Currently, CVS is primarily indicated for chromosomal studies, DNA analysis of genetic disorders and prenatal diagnosis of inborn errors of metabolism. For chromosomal studies, the main indications for CVS are: maternal age over 35 years, previous pregnancy with a chromosomal abnormality or multiple anomalies, parents with proved chromosome translocations, inversions and aneuploidies, X-linked diseases, history of recurrent miscarriage, abnormal ultrasound scan and decrease or the absence of amniotic fluid in the first trimester. The development of first-trimester screening methods for the detection of fetal chromosomal anomalies has increased the demand for CVS. In fact, although maternalrelated risk for fetal aneuploidy remains a common indication for CVS, the indication for CVS has evolved to become one of quick confirmation of an abnormal karyotype whenever chromosomal abnormality is suspected based on ultrasound scan or biochemical screening in the first trimester. Less common indications for fetal karyotyping are multiple miscarriages and pregnancies after assisted reproductive techniques. First trimester ultrasound screening for Down syndrome can occasionally bring to light a number of fetal abnormalities. Holoprosencephaly, omphalocele, cystic hygroma, diaphragmatic hernia and megacystis are well known features of either aneuploidies or other genetic syndromes. When they are detected in the first trimester, CVS is indicated for fetal karyotyping or molecular studies. DNA-based diagnoses of single-gene disorders, such as cystic fibrosis, hemophilia, muscular dystrophy and hemoglobinopathies, continue to expand with advancing technologies and the discovery of the additional disease-causing genes. Single gene disorders, which affect about $1 \%$ of livebirths, carry a high risk of recurrence and have unsatisfactory treatment so that prenatal diagnosis with termination of affected pregnancies is an important option for at-risk couples. Prenatal diagnosis of genetic disorders is based on the carrier detection procedures and genetic counseling of the couples at risk. Inborn errors of metabolism represent a vast group of disorders that are individually rare but together are a significant cause of human disease. Chorionic villi provide large amounts of metabolically active cytoplasm, therefore for many inherited metabolic diseases direct assay is possible, yielding diagnostic results within hours or a few days. Moreover, the amount of DNA obtained from a conventional sampling allows reliable analysis by recombinant DNA technologies. This is not the case with amniotic fluid cells, which provide too little DNA, which is frequently fragmented. Majority of these disease are very rare and new detection methods for specific disorders are constantly being reported so it is advisable to check with a specialists referral center on the current availability and preferred method for prenatal diagnosis. Some congenital infections such as rubella, toxoplasmosis, cytomegalovirus and parvovirus can also be detected by CVS.

CVS in multiple pregnancies require more experience, ability and an accurate planning of the procedure. The procedure is not complicated in cases with clearly separated placentas 
but it becomes a challenge in cases of fused or joined placentas, because in contrast to amniocentesis when one amniotic cavity can be marked with a dye, with CVS there is no technique to ensure that each sample has been obtained from a distinct placenta. To be sure to sample all fetuses one by one, and to reduce the risk of contamination, separate forceps and needles are inserted in succession and different samples are collected in close proximity to each cord insertion. A high level of expertise in technique of CVS is crucial. However, CVS can generally offer several technical advantages over midtrimester amniocentesis (Antsaklis et al.,2002). The easy evaluation of the membranes by ultrasound makes both the prediction of chorionicity and amnionicity and the identification of the affected twin(s) more reliable, the use of rapid analytical methods makes substantial changes in the uterine topography very unlikely, and if same-sex dichorionic twins are diagnosed, DNA polymorphism markers may be easily checked to assure retrieval of villi from the individual placentas. In the hands of experienced operators, CVS has the same efficacy as mid-trimester amniocentesis for genetic diagnosis of multiple gestations: diagnostic error, probably due to incorrect sampling, is between $0,3 \%$ and $1,5 \%$. Speaking of safety, carried out by expert physician, CVS appears at least as safe as amniocentesis (Brambati et al.,2001). Postprocedural loss rate after CVS in multiple pregnancies is somewhat higher than in singleton pregnancies but comparable to midtrimester amniocentesis. In cases where selective reduction is indicated the advantages of the first-trimester approach include a significantly lower emotional impact and a lower risk of clinical complications (Brambati et al.,2004)

\subsection{Laboratory considerations for chorionic villus sampling}

In the early development of CVS there was a high rate of incorrect results due to maternal cell contamination and misinterpretation due to placental mosaicism. In the early 1990s the laboratory failure rate was $2,3 \%$, which was significantly higher compared to amniocentesis. Nowadays CVS is considered to be a reliable method of prenatal diagnosis with a high rate of sucess and accuracy. Most centers report near 99\% CVS sucess rate with only $1 \%$ of the patients requiring a second diagnostic test ( amniocenteses or cordocenetsis) to clarify the results (Brun et al., 2003). Maternal cell contamination is the first cause of potential diagnostic errors which can occur after CVS.Obtained samples after CVS typically contain two cell lines: fetal i.e.placental villi and maternal i.e. decidua. It is posible that maternal cell line completely overgrow the culture and lead to incorect sex determination ans potentially to false- negative diagnosis. However, today, maternal cell contamination occurs in less then $1 \%$ of cases and usually does not limit the possibilities of accurate diagnosis. Contamination of samples with significant amounts of maternal decidual tissue is almost always due to small sampling size. In experienced centers in which adequate quantities of villi are avilable, this problem has disappeared. The second major cause of potential diagnostic error associated with CVS is placental mosaicism (Kalousek et al.,2000). The rate of placental mosaicism in the frst trimester CVS is $1-2 \%$. Although the fetus and placenta have a common ancestry, chorionic villus tissue will not always reflect fetal genotype. While initially placental mosaicism was considered as the main disadvantige of CVS in prenatal diagnosis, today it is an important marker for pregnancies at increased risk for growth retardation or genetic abnormalities. Two mechanisms can explain the occurance of placental mosaicism: mitotic error originally confined to the placenta and trisomic conceptus loosing of chromososme in the embryonic cell line. The most significant complication of 
placental mosaicism is uniparental disomy which is the case when both chromosomes originate from the same parent (Kotzot et al.,2001). The clinical concequence of uniparental disomy occurs when the involved chromososme carries an imprinted gene in which expression is dependent on the patern of origin. For example, Prader-Willi syndrome may result from uniparental maternal disomy for chromosome 15. Because of this, all cases in which trisomy 15 is confined to the placenta should be evaluated for uniparental disomyy by amniotic fluid analysis. There is also evidence that placental mosaicism might alter placental function leading to the fetal growth restriction. This is especially relevant to chromosome 16 where placental trisomy affects growth of both uniparental and biparental disomy fetuses in a similar manner. A decision of termination of pregnancy should not be done on the basis of mosaicism found on CVS. In such cases an amniocentesis should be offer to elucidate the extent of fetal involvement. Amniocentesis correlates perfectly with fetal genotype when mosaicism is limited to the direct preparation. When a mosaicism is observed in tissue culture, amniocentesis is associated with a false negative rate of about $6 \%$ and mosaic fetuses were reported to be born after normal amniotic fluid analysis (Los et al.,2001). Follow-up may include fetal blood sampling or fetal skin biopsy. However, the predictive accuracy of these additional tests is still uncertain.

\subsection{Transcervical versus transabdominal chorionic villus sampling}

In most cases, operator or patient choice will determine the sampling route, but the choice of the route is usually decided on a case-by-case depending on placental site. Anterior and fundal placentas are usually easily accessed transabdominally while lower, posterior located placentas are more accessible transcervically. However, operators must be skilled in both methods. Both techniques appear to be comparably efficient between 8 and 12 weeks, when the overall success rate after two sampling device insertions is considered to be very near to $100 \%$ (Philip et al.,2004).This efficiency has been confirmed in three national randomized trials of transabdominal vs.transcervical CVS (Brambati et al.,1991; Jackson et al.,1992; Smidt-Jensen et al.,1992). Although the data appear to confirm that the two techniques are equally effective in obtaining adequate amounts of chorionic tissue, transabdominal needling entailed a significantly smaller proportion of repeated device insertions (3.3 vs. $10.3 \%$ ) and of low weight specimens (3.2 vs. $4.9 \%$ ). Moreover, the complications due to undetected vaginal or cervical infection were much higher in the transcervical group. Additionally, speaking of safety, the Cochrane review showed that the transcervical CVS is more technically demanding than transabdominal CVS with more failures to obtain sample and more multiple insertions (Alfirevic et al.,2003). There are no differences in birth weight, gestational age at delivery, or congenital malformations with either method (Cederholm et al.,2003). Because of the specificity of the sampling route, transabdominal and transcervical sampling techniques are expected to have different types of contraindications. Vaginismus and stenotic or tortuous cervical canal, as well as myomas of the lower uterine segment, may severely hamper the introduction of either catheter or forceps. Active vaginal infection may also be an absolute contraindication to the cervical route. In the latter condition, vaginal and cervical culture and specific treatment do not seem sufficient to remove any risk of ascending infection. Transabdominal sampling may be relatively or absolutely contraindicated when obstacles such as intestines, large myomas or the gestational sac cannot be avoided. If olygohydramnios is present, transabdominal CVS may be the only approach available. 
Transabdominal sampling, in our experience, has definitely become the method of choice, and our preference for this approach is based on the shorter learning time, the lower rate of immediate complications, the higher practicality and success rates at the first device insertion, the lower hazard of intrauterine infection, the opportunity to extend sampling beyond the first trimester, and the wider range of diagnostic indications.

\subsection{Complications}

The benefits of earlier diagnosis of fetal genetic abnormalities by chorionic villus sampling (CVS) or early amniocentesis must be set against higher risks of pregnancy loss and possibly diagnostic inaccuracies of these tests when compared with second trimester amniocentesis. The overall pregnancy loss rate following CVS has been reported in a number of relatively large clinical studies, and the values range from 2.2\% to 5.4\% (Odibo et al.,2008). The date used for determining the associated risks of fetal loss due to CVS are presented in the literature as case series with detailed outcome and comparative studies of CVS group versus amniocentesis and transabdominal versus transcervical CVS. Data evaluating the safety of CVS compares amniocentesis comes primarily from three collaborative reports ( Canadian Collaborative group, 1989; Medical Research Council, 1977; Rhoads et al.,1989). The results of Canadian Collaborative group demonstrated equivalent safety of CVS compared to midtrimester amniocentesis There was a 7,6\% loss rate in the CVS group and a 7\% loss rate in the amniocentesis group. A multicentric U.S. (Rhoads et al.,1989) study found slightly higher fetal loss rate following CVS $(7,2 \%)$ compared to the one following midtrimester amniocentesis $(5,7 \%)$. A prospective, randomized, collaborative comparison of more than 3200 pregnancies, sponsored by the European Medical Council reported CVS having a 4,6\% greater pregnancy loss rate than amniocenetesis.Based on the presented data, CVS is associated with a slightly increased risk of fetal loss when compared to amniocentesis. Noteworthy, that excluding the results of the MRC study, CVS is associated with no more then $1 \%$ extra risk of fetal loss when compared to midtrimester amniocentesis. Also, the risks of fetal loss rate should not be compared between the studies since each study had its own criteria for total fetal loss (although most have described fetal loss before 28 weeks gestation). Moreover, while some have included only cytogenetically normal fetuses, others have evaluated a mixed population. The risk of fetal loss after CVS can also be obtained from the studies comparing CVS with early amniocentesis (Caughey et al.,2006). Most of these studies point to a relatively small risk of fetal loss (2-3\%) associated with CVS on the one hand and a significantly increased risk of fetal loss in the early amniocentesis gropu on the other hand. Logistic regression analysis of the procedure-related variables showed a significant association between fetal loss rate and maternal age, the lowest rates occurring in the youngest women $(1.22 \%)$ and the highest in the women of 40 years and over, while gestational age affected the abortion rate only at 8 weeks $(3.78 \%)$, no differences in the odds ratio being present at 9 to 12 weeks. Moreover, procedure related risk remained low later in pregnancy, and total fetal loss rates for CVS cases performed at 13-14 weeks and at least 15 weeks compared favorably with early and midtrimester amniocentesis respectively. Single-operator experience presents an estimated fetal loss after CVS of about 2-3\%. Although, single operator experience shows that the results ( fetal loss rate) of early procedures are better in the hands of skilled operators, this remains controversial. Transabdominal CVS is considered by many to be safer than the transcervical approach.However, this observation is heavily influenced by the data from the Danish study (Smidt-Jansen,1992).Moreover no significant difference found 
between those two approaches from two of three randomized trials comparing techniques.Based on these studies, as well as myny single center reports, we believe that the poor results from the Danish study ( where the Portex cannula was used) would not be repeated if the operators were equally good at the techniques being compared. Unfortunately, no study has randomly evaluated CVS versus non-sampled (with same risk) patients.

Among early post-procedural complications, spotting within a few hours has been more frequently observed in patients undergoing transcervical rather than transabdominal CVS (Brambati et al.1991). Other sequelae due to injury to the placental circulation include retroplacental hematomas and subchorionic hemorrhage. Significant amniotic fluid leakage after CVS is about 2-4 times less frequent when compared to early amniocentesis.

Localized peritonitis immediately after sampling occurs in very few cases, and only after transabdominal sampling, with an overall rate of $0.04 \%$. Intrauterine infection (acute chorionamnionitis) should be considered a potential, although very rare, complication of transcervical CVS, having been reported in $0.1-0.5 \%$ of cases, and in some large series no cases at all were observed (Paz et al.,2001). However, there is some concern about the role of less serious infection in women who experience fetal loss after transcervical CVS. Because transcervical CVS involves passage of a cannula or forceps through the cervical canal from the perineum and vagina, microbial colonization and infection, with consequent morbidity for both mother and fetus, may result (Cederholm et al.,2003).

Feto-maternal hemorrhage following CVS has been demonstrated by a significant increase in maternal serum a-fetoprotein in $40-72 \%$ of cases, and in $6-18 \%$ of these the amount of blood transfused was calculated to exceed $0.1 \mathrm{ml}$. Fetal hemorrhage should therefore be capable of initiating an immune response in RhD-negative women bearing an RhD-positive fetus. Moreover, an association between maternal serum a-fetoprotein increase and frequency of spontaneous fetal death has been suggested for the cases with the highest maternal serum a-fetoprotein levels (Mariona et al.,1986).

In general, the rate of fetal abnormalities after CVS is not different than in general population. Several case reports and cohort studies in the early 1990s have suggested a possible association between CVS and a cluster of limb defects and oromandibular hypogenesis. However, these findings were not repeated in other studies. The background risk of limb reduction defects (LRD) in the general population is low and varies between 1.6 and 4/10000. In an evaluation of CVS safety presented by WHO, LRD cases were observed in 5.3/10000. The possible mechanisms of LRD following CVS are unknown. However, there are three principal theories:

1. Vascular disruption caused by hemodynamic disturbances, vasoactive peptides or embolism

2. Amnion puncture with subsequent compression and entanglement of the fetus.

3. Immunological mechanisms causing increased apoptotic cell death

It is speculated that technical aspects of the procedure may have a bearing on the amount of placental trauma associated with the sampling procedure and the risk of limb deficiency. However, the rarity of limb deficiency following CVS means that none of the existing trials have the power to clarify the effect of technical factors on the risk. It also remains unresolved whether the risk of limb deficiency differs for transabbominal versus transcervical sampling ( 
Froster et al., 1996). Given the weight of current evidence supporting an association between early sampling and limb deficiency, it would be unethical to conduct a trial to investigate this prospectively.

No increased frequency of perinatal complications, i.e. preterm birth, small-for-dates neonates, perinatal mortality and congenital malformations, have been observed both in randomized and clinical control studies (MRC Working Party, 1992).

\section{Amniocentesis}

Amniocentesis is the invasive diagnostic procedure by which amniotic fluid is aspirated from pregnant uterus using transabdominal approach. This method was first performed as therapeutic procedure more than 100 years ago for decompression of polyhydramnios. Amniocentesis became a diagnostic procedure in 1950s when Bevis first used amniotic fluid for measurement of bilirubin concetration and prediction of the severity of Rhesus immunisation. Today amniocentesis is a significant diagnostic tool for prenatal detection of chromosomal as well as metabolic disorder. Tests performed on fetal cells found in the sample can reveal the presence of many types of genetic disorders, thus allowing doctors and prospective parents to make important decisions about early treatment and intervention (Wilson, 2005).

\subsection{Timing and technique}

For karyotyping amniocentesis is generally performed between 15 and 18 weeks of gestation with results usually available within three weeks. At this time, the amount of fluid is adequate (approximately 150ml), and the ratio of viable to nonviable cells is greatest. With the current technology amniocentesis is technically possible from 8 weeks of gestation but this is not usually recommended because there appears to be an increased risk of miscarriage when done at this time (Allen \& Wilson,2006). The advantage of early amniocentesis and speedy results lies in the extra time for decision making if a problem is detected. Potential treatment of the fetus can begin earlier. Important, also, is the fact that elective abortions are safer and less controversial the earlier they are performed. For assessment of the fetal lung maturity the amniocentesis can be used until term (Hanson et al.,1990). Before the procedure, genetic couceling is mandatory and a detailed family history should be obtained. The parents should be informed about the complications and limitations of the procedure same as for CVS. After genetic counseling, a "level two" ultrasound is then done to check for any signs of fetal abnormalities, to check the fetal viability, to determine the position of the fetus and of the placenta, to examine closely the main fetal structures, and to double check the gestational age (Hanson et al.,1990). Ultrasound is used also to determine the best location for placing the needle-a pocket of substantial amniotic fluid well away from the baby and umbilical cord. When amniocentesis first came into use, they were done "blind" (without continuous ultrasound guidance during the procedure), and this resulted in a number of disastrous outcomes, including occasional cases of horrifying fetal damage and death(Gratacos et al.,2000) .Modern amniocentesis is done with continuous ultrasound and is much less dangerous. For the amniocentesis, the mother lies flat on her back on a table. Iodine solution is swabbed onto her belly in order to cleanse the area 
thoroughly, and sterile drapes are placed around the area. After an appropriate sampling path has been chosen, a 20 to 22-gauge needle is introduced into a pocket of amniotic fluid free of fetal parts and a umbilical cord. The pocket should be large enough to allow advancement of the needle tip through the free-floating amniotic membrane that may occasionally obstruct the flow of fluid. The first $2 \mathrm{ml}$ of amniotic fluid are discarded to reduce the risk of contamination of the sample with maternal cells which could occasionally lead to false-negative diagnosis. The amount of withdrawn amniotic fluid should not exceed 20 to $30 \mathrm{ml}$ (Blessed et al.,2001).There is confirmed relationship between higher fetal loss and aspiration of $40 \mathrm{ml}$ of amniotic fluid and more. Continuous ultrasound during an amniocentesis allows the doctor to see a constant view of the needle's path, the location of fetus and to identify uterine contractions that occasionally retract the needle tip back into the myometrium. If the fetus moves near the needle's path at any point, the doctor can then reposition the needle, or if necessary, withdraw the needle and try again in a different location. Continuous ultrasound has eliminated a great deal of the risk formerly associated with amniocentesis (Johnson al.,1999). The procedure should be performed either free-hand or with the needle guide. The free-hand technique allows easier manipulation of the needle if the position of the target is altered by a fetal movement or uterine contraction. Alternatively, a needle guide allows more certain ascertainment of the needle entry point and a more precise entry determination of the sampling path. A needle guide technique is helpful for obese patients, in cases of oligohydramnios and for relatively inexperienced sonographer (Welch et al.,2006). After the fluid sample is taken, the doctor immediately checks the viability of the fetus. Both uterine and maternal abdominal wall puncture sites should be observed for bleeding and anti-D should be given to Rh negative women. In experienced hands and after 11 completed weeks of gestation the pure amniotic fluid aspiration has a success rate of $100 \%$. If the initial attempt to obtain fluid is unsuccessful, a second attempt in another location should be performed after reevaluation of the fetal and placental positions. If unsuccessful after two attempts, the patient should be rescheduled in several days. The technique of early amniocentesis is similar to amniocentesis performed at later gestational ages. However, in the first trimester there are two sacs, the amniotic cavity and the extra-embryonic coelome. The incomplete fusion of the amnion and chorion in early gestation may result in tenting of the membranes, which may necessitate more needle insertions. It is important to distinguish the two sacs ultrasonographically at the time of the amniocentesis, as the fluid in the extraembryonic coelome is jelly-like, difficult to aspirate, and has a different alpha-fetoprotein concentration than amniotic fluid. Retrieval of fluid from this sac should be avoided, as it will only rarely produce enough cells to allow a cytogenetic diagnosis (Sundberg et al.,1991). In order to assess whether amniotic fluid has been retrieved from both sacs in twin pregnancies, a marker (a dye or a biochemical substance) may be injected into the first sac. When the second sac is punctured, the absence of the marker in the amniotic fluid indicates that both sacs have been sampled. However, real-time ultrasound allows visually guided amniotic fluid sampling from both sacs, thus making dye-injection obsolete (Pijpers et al.,1988). Whether amniocentesis in twin pregnancies should be performed by using one or two needle insertions remains to be shown. A single needle insertion could reduce the abortion risk, but may on the other hand create the problems of amniotic band syndrome or a monoamniotic twin pregnancy, or give rise to cytogenetic problems (Millaire et al.,2006). 


\subsection{Indications}

Since the mid-1970s, amniocentesis has been used routinely to test for Down syndrome by far the most common, nonhereditary, genetic birth defect, affecting about one in every 1,000 babies. By 1997, approximately 800 different diagnostic tests were available, most of them for hereditary genetic disorders such as Tay-Sachs disease, sickle cell anemia, hemophilia, muscular dystrophy and cystic fibrosis (Summers et al.,2007).

Amniocentesis is recommended for women who will be older than 35 on their due-date. It is also recommended for women who have already borne children with birth defects, or when either of the parents has a family history of a birth defect for which a diagnostic test is available. Another reason for the procedure is to confirm indications of Down syndrome and certain other defects which may have shown up previously during routine maternal blood screening (Fergal et al.,2005). The risk of bearing a child with a nonhereditary genetic defect such as Down syndrome is directly related to a woman's age-the older the woman, the greater the risk. Thirty-five is the recommended age to begin amniocentesis testing because that is the age at which the risk of carrying a fetus with such a defect roughly equals the risk of miscarriage caused by the procedure-about one in 200. At age 25, the risk of giving birth to a child with this type of defect is about one in 1,400; by age 45 it increases to about one in 20. Nearly half of all pregnant women over 35 in the United States undergo amniocentesis and many younger women also decide to have the procedure. Notably, some $75 \%$ of all Down syndrome infants born in the United States each year are to women younger than 35 (Jacobson et al.,2004).

One of the most common reasons for performing amniocentesis is an abnormal alphafetoprotein (AFP) test. Because this test has a high false-positive rate, another test such as amniocentesis is recommended whenever the AFP levels fall outside the normal range (Sepulveda et al.,1995).

\subsection{Laboratory considerations for amniocentesis}

The cells within the amniotic fluid arise from fetal skin, respiratory tract, urinary tract, gastrointestinal tract and placenta. After obtained fetal cells, they are put into tissue culture, either in flasks or more often on coverslips. After 3 to 7 days of growth, sufficient mitoses are present for staining and karyotype analysis. Viable cells in the amniotic fluid are cultured and used for karyotyping, and investigation of metabolic and biochemical disorders. Uncultured cells may now be used to detect specific chromosome aberrations by using chromosome specific probes and fluorescent in situ hybridization (FISH) on interphase cells, but complete karyotyping is not yet possible on uncultured cells (Pergament,2000). Amniocyte culture is quite reliable, with failure occurring in less than $1 \%$ of cases. The culture failure rate increase with falling gestational age and it seems to occur more often in fetal aneuploidy. Chromosomal mosaicism most frequently results from postzygotic nondisjunction but can also occur from meiotic errors with trisomic rescue. The most common etiology is pseudomosaicism where the abnormality is evident in only one of several flasks or confined to a single colony on a coverslip. In this case the abnormal cells have arisen in vitro, are not present in the fetus, and are not clinically important. Alternatively, true fetal mosaicism is rare, occurring in $0,25 \%$ of amniocentesis but can be clinically important, leading to phenotypic or developmental abnormalities. Maternal cell 
contamination may cause misdiagnosis, if only maternal cells are examined or mosaicism is suspected. The rate of maternal cell contamination is 1-3 per 1000 cases, but this figure should probably be doubled as maternal cell contamination is only detected when the fetus is male (Tepperberg et al.,2001). A large study (Welch et al.,2006) sought to relate the frequency of maternal cell contamination in amniotic fluid samples that were submitted to a single laboratory for cytogenetic analysis to the experience and training of the physician who performed the amniocentesis.

Fluorescence in situ hybridization (FISH) probes are relatively short fluorescently labeled DNA sequences that are hybridized to a known location on a specific chromosome and allow for determination of the number and location of specific DNA sequences. Presently, it is suggested that FISH analysis not be used as a primary screening test on all genetic amniocenteses because of its inability to detect structural rearrangements, mosaicism, markers, and uncommon trisomies. Because all abnormalities would be detectable by tissue culture, FISH analysis is not cost effective. Presently, most laboratories use FISH to offer quick reassurance to patients with an unusually high degree of anxiety or to test fetuses at the highest risk, such as those with ultrasound anomalies. It is also beneficial in cases where rapid results are crucial to subsequent management, such as advanced gestational age (Sawa et al., 2001).

\subsection{Complications}

Amniocentesis is not without maternal and fetal complications and should be undertaken with due regard to the risks involved.

\subsubsection{Maternal}

The risk of intervention for the mother is minimal. The risk of an amnionitis after amniocentesis is less than $0,1 \%$ and the risk of a severe maternal infection reaches $0.03 \%-0.09 \%$ (Wurster et al.,1982). In a retrospective survey of 358 consecutive amniocentesis ( Pergament, 2000) there were two patients who developed amniotic fluid peritonism and one with minor intraperitoneal bleeding. Amniocentesis is not associated with severe pregnancy complications such as placental abruption or placenta praevia. On the other hand after amniocentesis there is an increased risk of complications related to amniotic cavity, membranes and hypotonic uterine dysfunction (Cederholm et al.,2003).Feto-maternal hemorrhage occurs during amniocentesis in one out of six women, and may therefore theoretically give rise to subsequent isoimmunisation. In a prospective cohort study (Tabor et al.,1987) the immunization rate was $1.4 \%$. The observed $1.4 \%$ immunization rate is not different from the spontaneous immunization rate. In spite of these findings, and since Rh-immune serum globulin is apparently harmless to the fetus and mother, its use is recommended in nonsensitized Rhnegative mothers after amniocentesis Practice differs between countries regarding whether this recommendation is followed or not. In American controlled study anxiety and depression varied similarly in women having amniocentesis and in control women. However, among women having amniocentesis due to advanced maternal age, the anxiety level was increased while awaiting the results of the test (Phipps et al.,2005).

\subsubsection{Fetal}

The major risk of mid-trimester amniocentesis is fetal loss. Two types of loss should be considered: (1) total pregnancy loss rate postprocedure, which includes both background 
pregnancy loss for that gestational age and procedure-related loss, and (2) procedure related pregnancy loss. The total post-amniocentesis loss rates are derived from studies of populations of pregnant women who underwent amniocentesis, with a control group consisting of populations of pregnant women who had another procedure. The amniocentesis-related pregnancy loss rates are derived from studies of pregnant women who had amniocentesis compared with a "no procedure" control group. A study published by Eddleman et al. suggests that the procedural loss rate of amniocentesis may be much smaller than previously reported, further challenging the indications for invasive testing in the context of a traditional "risk-benefit" ratio (Eddleman et al.,2006). Although the committee agrees that it is timely to re-evaluate this issue, it is believed Eddleman's conclusion that the rate of miscarriage due to amniocentesis of $0.06 \%(1 / 1600)$ is misleading and should be interpreted with caution. The study is based on a secondary analysis of data from the "First and Second Trimester Evaluation of Risk for Aneuploidy" (FASTER) trial, the primary goal of which was to compare first and second trimester noninvasive prenatal genetic screening methods. Among the 35003 women enrolled the rate of spontaneous fetal loss prior to 24 weeks' gestation in the study group was $1 \%$, not statistically different from the control group rate of $0.94 \%$. The risk of miscarriage due to amniocentesis was reported to be the difference between these two rates, which was $0.06 \%$. Letters to the editor have criticized the FASTER conclusion. Nadel (Nadel,2007) concluded that the likelihood of amniocentesis resulting in the loss of a euploid fetus is less than $0.5 \%$.Smith (Smith,2007) commented that the methods used to include or exclude pregnancy termination patients resulted in the paradox of a statistically significant increase in spontaneous abortion for women not having amniocentesis with a positive screen and women who were aged 35 years or over. The lowest rate of risk for genetic amniocentesis derived from the literature is about 1 in 300 (Wilson,2007). In counseling patients prior to amniocentesis, it is important to convey to patients that at their stage of pregnancy there is still a background pregnancy loss rate, and that amniocentesis will contribute an additional procedure related loss rate. The notion of background population or individual loss rate is important, as the patient will not be able to determine whether her pregnancy loss was "background" or "procedural."Counselling should provide a woman with the total pregnancy loss rate to enable her to fully understand the possible sequelae of her decision. Individual procedural risks may be required for counseling because of the real variables that contribute to the population or individual background risk.

\section{A. Patient factors}

1. Maternal age/ paternal age (Kleinhaus et al.,2006)

2. Past reproductive history

3. Pre-existing maternal conditions (diabetes, hypertension, infertility, autoimmune)

4. Pregnancy/uterine (assisted reproductive techniques, vaginal bleeding, uterine fibroids, placental location, amniotic fluid loss, oligohydramnios, retro chorionic hematoma, single vs. multiple gestations)

5. Screening methodology

i. $\quad$ timing (first trimester, second trimester, first and second trimester)

ii. technique (ultrasound alone, biochemistry, biochemistry and ultrasound, nuchal translucency +/- biochemistry, single or multiple soft markers or congenital anomalies) 


\section{B. Procedure factors}

1. Amniocentesis needle size variation

2. Operator experience

3. Ultrasound guided (freehand; needle guide)

4. Uterine/placental location

5. Maternal BMI

\section{Postprocedure factors}

1. Rest for 24 hours or normal activity (no evidence-based comparisons available)

2. Complications (ruptured membranes, infection)

Increasing maternal and paternal age are significantly associated with spontaneous abortion, independent of amniocentesis and multiple other factors (Kleinhaus et al.,2006). Also pre-existing maternal conditions, as well as assisted reproductive techniques and multiple gestations are "per se" risk factors for increase fetal loss (Bianco et al.,2006). Amniocentesis before 14 weeks gestation has an adverse effect on fetal loss (Alfirević et al.,2007). Rupture of membranes is an uncommon complication of genetic amniocentesis. Theoretically, a thin needle may have both advantages and disadvantages for fetal loss. One would expect a thin needle to cause a smaller hole in the membranes and to be less traumatic, thereby decreasing the risk of amniotic fluid leakage and feto-maternal hemorrhage. On the other hand, a thin needle increases the procedure time, and increased sampling time might be associated with an increased risk of chorio-amnionitis and fetal loss (Weiner,1991). It seems reasonable to assume the fetal loss to be lower if the operator has performed a large number of invasive procedures than if he/she is inexperienced. (Milunsky,2010). The number of annual procedures needed for amniocentesis to be safe is not known, and the recommendation of at least 150 amniocenteses per year is not based on scientific evidence. There is indirect evidence from nonrandomized studies that ultrasound guided amniocentesis is safer than blind amniocentesis, because feto-maternal hemorrhage occurs less often if the procedure is performed under ultrasound guidance than if it is done blindly and feto-maternal hemorrhage may be associated with an increased risk of fetal loss (Papantoniou et al.,2001). In the study by Weiner and colleagues, there was some evidence that the rate of fetal loss after amniocentesis increased with the number of needle insertions. On the other hand they did not find increased fetal loss after transplacental passage of the amniocentesis needle than after non-transplacental passage. Possibly, the most important thing is to perform the procedure as atraumatically as possible. Therefore, the puncture site that gives easiest access to a pocket of free fluid should be chosen. If the placenta can be easily avoided, it is probably wise to avoid it. Whether the amount of amniotic fluid removed has any effect on fetal loss rates is not known, but it is probably wise to remove as little as possible (usually $15-20 \mathrm{ml}$ is enough to obtain a diagnosis). Spontaneous reseal of ruptured membranes after genetic amniocentesis can occur with conservative management and end with a favorable pregnancy outcome (Phupong \& Ultchaswadi,2006).

The Table 1 summarizes the recent published reports (randomized controlled trials and cohort studies with or without a control group; the control group may have no procedure or an alternative procedure), showing a range of post mid-trimester amniocentesis losses of 0.75 to $2,1 \%$.The FASTER study pregnancy loss difference (amniocentesis; no amniocentesis) is a clear outlier within these controlled study groups and reflects that this 
study's method of analysis underestimated the procedure-related pregnancy loss rate following mid-trimester amniocentesis by excluding the terminated pregnancies in the amniocentesis group, resulting in a lower intrinsic rate of pregnancy loss for this group than for the control group.

In conclusion there is no single percentage (or odds ratio) that can be quoted as the risk of pregnancy loss following midtrimester amniocentesis in singleton pregnancies. The risks unique to the individual and is based on multiple variables, as summarized in this opinion. The best estimate range to consider for the increased rate of pregnancy loss attributable to amniocentesis is $0.6 \%$ to $1.0 \%$ but may be as low as $0.19 \%$ or as high as $1.53 \%$ on the basis of the confidence intervals seen in the various studies.

The fetal loss rate in multiple gestations has not been estimated in a controlled trial and is difficult to determine due to the increased miscarriage rate per se in twin pregnancies. An increased post-amniocentesis abortion rate in multiple gestations may be expected, since most operators use more than one needle insertion, a variable associated with an increased fetal loss rate (Toth-Pal et al., 2004). In the largest Israel study fetal loss among bichorionic twin gestations undergoing genetic amniocentesis was compare with singletons undergoing the procedure and untested twins. Fetal loss was 2,73\% in the first group, compared to 0,6\% and $0,63 \%$ in the other two groups. It may thus be concluded that the risk of early fetal loss is apparently higher in twins undergoing amniocentesis than in untested twins or tested singletons. These data can be of value in counseling parents of twins because of the increased number of gestations resulting from fertility programs and the elevated risk of chromosomal abnormalities in twin pregnancies (Yukobowich et al.,2001). Whether amniocentesis in twin pregnancies should be performed by using one or two needle insertions remains to be shown. A single needle insertion could reduce the abortion risk, but may on the other hand create the problems of amniotic band syndrome or a mono-amniotic twin pregnancy, or give rise to cytogenetic problems (Wapner et al.,1993).

Considering perinatal mortality et morbidity, amniocentesis does not affect the preterm birth rate, the stillbirth rate or the perinatal mortality rate. This procedure does not affect neither the mean birth weight. In early experience with amniocentesis, needle puncture of the fetus was reported in $0,1 \%$ to $0,3 \%$ of cases (Karp \& Hayden, 1977) and was associated with fetal exsanguinations (Young et al., 1977), intestinal atresia (Swift et al., 1979), uniocular blindess, porencephalic cysts, peripheral nerve damage and intestinal atresia (Karp \& Hayden,1977) Continuous use of ultrasound to guide the needle minimizes needle puncture of the fetus and in the hands of experienced operators those are extremely rare complications. The British study ( Medical Research Study, 1978) also found an increase in postural deformities such as talipes and congenital dislocation of the hip. The possible mechanism of this deformity is compression due to olygohydramnios or tissue injury from the amniocentesis needle. This study was criticized for biases in the selection of the control patients who were younger, had less parity, entered later in the gestation in the study and some of the matched controls were replaced with other controls.No long-term adverse effects have been demonstrated in children undergoing amniocentesis. Finegan and colleagues (Baird et al.,1994) showed that the offspring of women who had had amniocentesis were no more likely than controls to have a registrable disability (such as hearing disabilities, learning difficulties, visual problems, and limb anomalies) during childhood and adolescence. At the ages of 4 and 7 years, there was no difference between the two groups regarding child social competence, behaviour, growth and health. The 
results suggest that the wide range of developmental and behavioural variables studied is not influenced by removal of amniotic fluid in the mid-trimester.

A. Total pregnancy loss rates post amniocentesis

\begin{tabular}{lccccc} 
Study & Type & $\begin{array}{c}\text { Mid-trimester } \\
\text { amniocentesis }\end{array}$ & Control & $\begin{array}{c}\text { Post-amniocentesis } \\
\text { loss rate }\end{array}$ & Significance \\
\hline Reid (1999) & C & 3953 & - & $0,7 \%$ & - \\
Antsaklis (2000) & C & 3910 & EA 5324 & $2,1 \% / 1,5 \%$ & $0,95 \%$ \\
Horger (2001) & RCT & 4600 & - & $0,83 \% / 0,46 \%$ & - \\
Caughey (2006) & C & 30893 & CVS9886 & & - \\
\hline
\end{tabular}

B. Procedure-related pregnancy loss rate

\begin{tabular}{|c|c|c|c|c|c|}
\hline Study & Type & $\begin{array}{l}\text { Mid-trimester } \\
\text { amniocentesis }\end{array}$ & $\begin{array}{c}\text { Control } \\
\text { (no procedure ) }\end{array}$ & $\begin{array}{l}\text { Procedure -related } \\
\text { Loss rate } \\
\text { (loss rate amnio group: } \\
\text { loss rate no procedure gr }\end{array}$ & $\begin{array}{l}\text { Significance } \\
\text { oup) }\end{array}$ \\
\hline Muller (2002) & $\mathrm{C}$ & 3472 & 47004 & $0,7 \%(1,12 \% ; 0,42 \%)$ & $95 \%$ CI 0,39-1,13 \\
\hline Kong (2006) & $\mathrm{C}$ & 3468 & 1125 & $\begin{array}{c}0,86 \% \text { ( corrected for } \\
\text { Background loss rate ) }\end{array}$ & $95 \%$ CI $0,19-1,53)$ \\
\hline FASTER(2006) & C & 3096 & 31907 & $0,06 \%(1 \% ; 0,94 \%)$ & $95 \% \mathrm{CI} 0,26-0,49$ \\
\hline Seeds (2004) & Review & 11372 & 12097 & $0,6 \%(1,68 \% ; 1,08 \%)$ & $95 \%$ CI $0,31-0,9$ \\
\hline \multicolumn{6}{|c|}{$\begin{array}{l}\text { RCT: Randomized controlled trial; C: cohort/case-control study; CVS: chorionic villus sampling (TA } \\
\text { transabdominal; TC: transcervical); EA: early amniocentesis; } \\
\text { RR: relative risk; CI: confidence interval; NS: non-significant difference. } \\
\text { * Study group: women 20-34 years of age having amniocentesis for increased risk of aneuploidy or } \\
\text { maternal infection; control group: women 20-34 years of age at } \\
\text { low risk but having amniocentesis }\end{array}$} \\
\hline
\end{tabular}

Table 1. Summary of studies with mid-trimester amniocentesis population

\subsection{Early amniocentesis}

The desire for a first-trimester diagnosis stimulated interest in the feasibility of performing amniocentesis under 15 weeks gestation including first trimester. The major advantage of early amniocentesis (9 to 14 weeks' gestation) is that results are known much more earlier. This procedure which was introduced in the late 1980s, is technically the same as a 'late' procedure except that less amniotic fluid is removed. The $15 \mathrm{ml}$ amniotic fluid at this week of pregnancy is a significant amount, while the extremities are in a critical period for the development. Ultrasound needle guidance is considered to be an essential part of the procedure because of the relatively small target area. The presence of two separate membranes (amnion and chorion) until 15 weeks' gestation creates an additional technical difficulty. Only the amniotic (inner) sac should be aspirated, because the outer sac does not contain sufficient numbers of living fetal cells. It has been reported that there is a culture failure ranging from $0,5-2,5 \%$. The karyotyping success rate may be increased by using filter 
techniques in which amniotic cells are retained on a filter after aspiration while the rest of the amniotic fluid (cell free) is reinjected into the amniotic cavity (Alfirević et al.,2007).

Fetal complications related to early amniocentesis were expected to be higher than those related to mid-trimester amniocentesis because of the higher amount of removed amniotic fluid (Johnson et al., 1999). Since a controlled trial has not yet been done, the complications following early amniocentesis has been compared to that following chorionic villus sampling (CVS) or amniocentesis in week 16-18. To determine the safety and accuracy of early amniocentesis, a randomized, multicenter Canadian study (Meier et al.,2005) compared the procedure to second-trimester amniocentesis.Among the women in the early amniocentesis group, $1 \%$ gave birth to infants with a foot anomaly. By comparison, only $0.1 \%$ of those in the second-trimester group gave birth to infants with this deformity a proportion similar to that found within the general population.Both the U.K. and Danish studies (Tabor et al., 1986) found an increase in respiratory distress syndrome and pneumonia in neonates from the mothers who underwent early amniocentesis. It may be that altered amniotic fluid volume after amniocentesis or subsequent chronic amniotic fluid leakage interferes with normal lung development and lung structure at term, thus giving rise to pulmonary hypoplasia and consequently to RDS in the newborn. Whether these antenatal and neonatal changes have any longterm impact on lung development remains to be shown. The study, funded by the National Institute of Child Health and Human Development (Philip et al.,2004) compared the rate of fetal loss between early amniocentesis and CVS. The combined outcome of spontaneous loss before 20 weeks and procedure-related termination occurred slightly more often after amniocentesis than after CVS, with risk most increased when amniocentesis was performed during week 13. In addition, incidence of talipes equinovarus (clubfoot) was fourfold higher after amniocentesis than after CVS, again, most cases occurred when amniocentesis was performed during week 13.

Early amniocentesis appears to be as accurate as CVS and mid-trimester amniocentesis. Amniocentesis at 13 weeks gestation carries a significantly increase risk of talipes equinovarus and respiratory illness compared with CVS and mid-trimester amniocentesis and also suggests an increase in early, unintended pregnancy loss. The safety of amniocentesis before 14 weeks gestation is uncertain. Until its safety can be ensured, it is best to delay routine sampling until week 15 or 16 of pregnancy.

\section{Cordocentesis}

Cordocentesis is an invasive method of obtaining fetal blood from umbilical cord using transabdominal approach. This method first described in 1983 by Daffos and coworkers offers advantage in efficacy and safety over the fetoscopic methods previously used to obtain fetal blood and nowdays almost completely abandoned (Daffos et al.,1985). The main target for obtaining fetal blood is the umbilical vein. Other possible targets for fetal blood sampling are fetal heart ventricles and the intrahepatic tract of the umbilical vein (Antsaklis et al., 1992)

\subsection{Timing and technique}

Depending on the indication, cordocentesis can be performed from about 18 completed weeks of gestation until the end of the pregnancy. When imaging and placental conditions 
are optimal, it can be done as early as 15 completed weeks. It is usually performed on an ambulatory basis. It requires a high-resolution ultrasound scanner, an experienced team and a laboratory specializing in fetal blood analysis (Sirirchotiyakul et al.,2000). The most favorable puncture site is the placental insertion of the umbilical cord, as the cord is the least mobile at that location. A 20-22 gauge needle is used. A stable needle is important, especially with the posterior placenta, so that the needle will not bend on the relatively long path to the umbilical cord insertion (Ghezzi et al.,2001). Blood is drawn from the umbilical vein with a $1 \mathrm{ml}$ syringe. Blood samples must be immediately examined to identify to purity of the sample and the results of the analysis can be significantly altered in case it has been contamined by maternal blood or amniotic fluid. A free loop of umbilical cord or the fetal insertion of the cord can also be used for puncture. Intra-abdominal puncture of the umbilical vein is yet another option. It is most difficult to puncture a free loop of umbilical cord. Attempts to puncture free loops often result in the cord being pushed away by the needle (Liaou et al.,2006). Besides the large-caliber vein, it is also possible to sample blood from one of the two smaller-caliber umbilical arteries. This procedure, however, carries a risk of vasospasm with subsequent fetal bradycardia and/or profuse afterbleedind and therefore puncture of the umbilical vein is always preferred. Fetal heart is an alternative sampling site and this technique can be used when access to the fetal circulation must be obtained at gestational age less than 17-18 weeks gestation or if an emergency blood transfusion is required.

\subsection{Indications}

Indications for cordocentesis have changed regarded to past decade. In fact the list is shorter than a decade ago because the noninvasive methods have rendered cordocentesis less important. However, some specific metabolic, hematologic or gene disorders are still testable only by fetal blood sampling. Cordocentesis is most commonly used for rapid fetal karyotyping (Shah et al., 1990). This is done in cases with ambiguous chromosomal findings from amniotic cell culture or CVS. The results can be obtained in 48-72 hours by leukocyte culture of the fetal sampled blood. This advantage of rapid karyotyping can also be used when ultrasound reveals an abnormality that is associated with chromosome disorders or in cases of an abnormal triple test. On the other hand some essentials blood tests are replaced by amniocentesis due to PCR techniques for gene amplification and the emergence of many new genetic markers. Various fetal infections can be diagnosed in the fetal blood: rubella, cytomegalovirus, toxoplasmosis, varicella and parvovirus B19 (Valente et al., 1994). For detection a fetal infection cordocentesis is not performed before 22 weeks of gestation because IgM antibodies occur in fetal blood after 20 weeks of gestation. Various blood diseases can be diagnosed using cordocentesis: hemoglobinopathies, coagulopathies, immune deficiencies and trombocytopenias (Burrows and Kelton, 1993). Determination of the platelet count in congenital thrombocytopenias provides important information on the intrauterine risk to the fetus which is particularly applies to alloimune thrombocytopenia. If this disease is confirmed intrauterine therapy with platelets should be performed to avoid fetal cerebral hemorrhage. In disorders that can lead to severe fetal anemia as a result of hemolysis ( $\mathrm{Rh}$ or Kell alloimmunisation, parvovirus B19 infection) cordocentesis can directly determine the degree of anemia and provide a specific basis for planning an intrauterine transfusion (Bowman, 1991). The use of Doppler peak velocity to assess the 
degree of fetal anemia reduce the need for fetal blood sampling. However, cordocentesis is always indicated when history, maternal titers or MCA Doppler show a risk of anemia.

Correlation between biophysical profile scoring (BPS) and fetal PH on cordocentesis, reduce percentage of fetal blood sampling in the determination of fetal blood gases and acid-base status, because BPS can be safely use to indicate fetal PH without invasive method. But because neither the BPS patterns nor Doppler findings provide clear-cut evidence of fetal compromise in all cases, cordocentesis can be a useful adjunct to the noninvasive tests, especially in cases of severe growth retardation. In cases with abnormal Doppler flow with a normal BPS score, cordocentesis can confirm or exclude chronic fetal asphyxia.

\subsection{Complications}

The overall complication rate of cordocentesis is slightly higher than that of amniocentesis. Besides the risk that are the same as for amniocentesis such as: abortion, membrane rupture and chorioamnionitis, there are additional risks that are specific for cordocentesis. Fetal loss rate related to cordocentesis reported to be as high as 6-7\% in centers with low experience, but in experienced hands the rate is as low as $1-2 \%$. Overall pregnancy loss rate depends largely on the fetal condition for which cordocentesis is done. The rate of pregnancy loss is worse in cases of fetal anomalies and abnormal karyotype (Tongsong et al.,2001).Unfortunately no controlled trials are yet available and it is not quite clear what is the fetal loss rate to quote to patients, because most clinical series contain many high risk cases such as stated before. The most common complication of cordocentesis is fetal bradycardia. The rate of fetal bradycardia reported in literature is $6,6 \%$. In most cases it is transient, self-limited and with no long-term concequences. It is related to uterine contraction directly at the cord insertion or fetal movement against the umbilical cord by the contraction. Profound or prolonged bradycardia occurs in less than $3 \%$ of cases and it is associated with umbilical artery vasospasm after puncture of the umbilical cord or tetanic uterine contraction, which is rar. Early gestational age and hydrops fetalis correlated significantly with the development of bradycardia at cordocentesis. The other risk groups, including fetuses with intrauterine growth retardation, the puncture site, and the number of puncture attempts did not correlate with fetal bradycardia (Preis et al.,2004). Transient bleeding from the umbilical cord puncture, called the "jet phenomenon" is a relatively common, innocuous finding after cordocentesis and it lasts no more than 2 minutes.The bleeding from the artery is reported to be longer than that from the vein. Differences among centers with respect to bleeding may relate to the size of the needle used and the technique employed.Bleeding over 300 seconds or massive hemorrhage occurs less than once per 200 cordocentesis. When this occurs a viable fetus should be delivered by emergency cesarean section. Hematomas of the cord have been observed in pathologic specimens with the freehand technique, although most are not associated with adverse sequelae (Kay et al.,2011). The incidence of symptomatic cord hematoma causing significant fetal bradycardia is very low. The risk of amnionitis is approximately $1 \%$ when the freehand technique is used and less than $0.3 \%$ when the needle-guided technique is used. Rarely, chorioamnionitis can lead to the development of maternal sepsis and adult respiratory distress syndrome.

Maternal complications are also seen. Cordocentesis lasts longer than amniocentesis, so the mother will more likely be anxious and have more discomfort. On the other hand, 
cordocentesis is less uncomfortable than CVS, so the patients will less complain of pain and contractions.Acute rupture of membranes and preterm labor are very rare complications.

Fetal-maternal transfusion has been reported after both cordocentesis and amniocentesis, especially when the placenta was anterior. It is imperative that Rh-negative women be given $\mathrm{Rh}$ immunoglobulin after a procedure unless the fetus is known to be Rh-negative or the patient is already sensitized (Rujiwetpongstorn et al.,2005)

The safety of cordocentesis is believed to be both technique-dependent and experiencedependent. Fewer punctures are reported with the freehand technique, but a lower fetal/neonatal loss rate is reported with the needle-guided technique. The rate of bleeding is reported to be reduced with the needle-guided technique and with the use of smaller gauge needles. Several investigators have found a greater number of complications among their first 30 procedures.

\section{Other invasive diagnostic procedures}

On infrequent occasions, analysis of other fetal tissues may be required. Because they are only rarely required, their use is usually confined to only a few regional referral centers in hopes of limiting procedural risk. Fetal skin biopsy is indicated for diagnosis of some type of genodermatosis or congenital dermoepidermic disorders which is expected to be lethal in short or medium terms. Those disorders are: bullous epidermolysis, anhidrotic ectodermic dysplasias, keratinization disorders and pigmentary atopies (Elias et al.,1994). It can also be helpful in the workup of fetal mosaicism for some chromosomes, such as 22 chromososme, which are known not to be manifest in fetal blood. Fetal muscle biopsy is used to diagnose Duchenne's muscular dystrophy in a male fetus if DNA testing is not informative (Nevo et al.,1999). It can also be used to detect other hereditary myopathies as long as there is some clinical family history of these disorders. Fetal liver biopsy was the only means of diagnosing fetuses with inborn errors of the urea cycle such as ornithine transcarbamylase deficiency, carbamoylphosphate synthetase deficiency and other disorders expressed only in the liver such as von Gierke glycogen-storage disease type IA and primary hyperoxaluria type I (Haberle et al.,2004). However, most of these conditions are now diagnosable by DNA analysis (without the need for histology and enzymatic assays) of cells extracted from either chorionic villi or amniocytes. Direct genetic analysis of chorionic villi is feasible, fast and specific and can be regarded as the primary choice for prenatal diagnosis of these rare conditions. The procedure which is used more frequent than the previous described is aspiration and biochemical analysis of fetal urine for the evaluation of fetal renal function. This evaluation is essential in determination of fetuses whose kidneys are not irreversible damaged and who will have the benefit from intrauterine derived therapy.The biochemical markers that have close relation with the renal function are defined by $\mathrm{Na}, \mathrm{Cl}$, beta-2 microglobuline and osmotic urine (Troyano et al., 2002).Other punctures on fetal tumor formations such as teratomas or liquid collections such as pericardiocentesis do not have an acceptable justification from a diagnostic point of view, as the echographic evaluation and the present application of biophysical methods give an acceptable identification of their vascularisation and origin, including those of suspicious neoplasm. 


\section{Conclusion}

More than 40-year history of invasive procedures has seen a rise and than a fall in the degree of invasiveness of the procedures. The decades of invasive diagnostic procedures have given us a unique opportunity to study the fetus. They have contributed to our understanding of human fetal physiology, metabolism, and disease. However, the introduction of non-invasive procedures has diminished the need for some invasive procedures, in the first place for cordocentesis. As molecular genetics shrinks the role of cordocentesis for prenatal diagnosis of hereditary disease and as cytogenetic techniques make inroads that supplant the need for fetal blood sampling to obtain a rapid karyotype, it is likely that there will be fewer indications for cordocentesis in the next decade. A diminished role for cordocentesis will demand further regionalization of care in order for some persons to maintain the skill and further the knowledge base of normal fetal physiology and fetal disease. On the other hand amniocentesis still remains the gold standard for karyotyping, especially now that rapid diagnostic methods are available. Will nowdays invasive proceduers suffer the same fate as fetoscopy-here one day, gone another-or will the indications for them gradually be refined, limiting its practice to situations not suitable for noninvasive fetal testing remains to be shown. Invasive procedures may become obsolete when reliable non-invasive prenatal diagnosis becomes available.

\section{References}

Allen, VM.; Wilson, RD.(2006). Pregnancy outcomes after assisted reproductive technology. Joint SOGC-CFAS Guideline . J Obstet Gynaecol Can ,vol.28,No.3,(March 2006),pp.220-233

Alfirevic Z, Sundberg K, Brigham S. Amniocentesis and chorionic villus sampling for prenatal diagnosis, Cochrane Database Syst Rev. 2003;(3):CD003252

Alfirević,Z.;Sunberg,K.;Brigham,S.(2007).Amniocentesis and CVS for prenatal diagnosis review. The Cohrane Collaboration. Issue 4.John Wiley\&Sons,London

Antsaklis,A.;Papantoniou,N.;Vinzileos,A.(1992). An alternative method of fetal sampling for the prenatal diagnosis of hemoglobinopathies. Obstetr Gynecol,vol.73,No.4,(April 1992),pp.630

Antsaklis, A.; Papantoniou, N.; Xygakis, A.;Mesogitis, S.; Tzortzis ,E.;Michalas, S. (2000).Genetic amniocentesis in women 20-34 years old: associated risks. Prenatal diagnosis,vol.20,No.1,(January 2000),pp.247-250

Antsaklis,A.;Souka,AP.;Daskalakis,G.;(2002). Second trimester amniocentesis versus CVS in multiple gestations. Ultrasound Obstet Gynmecol, vol.20,No.5,(May2002),pp.476

Blessed ,WB.; Lacoste, H.;Welch RA.(2001). Obstetrician-gynecologists performing genetic amniocentesis may be misleading themselves and their patients. Am J Obstet Gynecol ,vol.184,No.3,(March 2001),pp.1340-1344.

Bianco, K.; Caughey, AB.; Shaffer, BL.; Davis, R.;Norton, ME.(2006). History of miscarriage and increased incidence of fetal aneuploidy in subsequent pregnancy. Obstet Gynecol ,vol.107,No.5-6,(June 2006),pp.1098-1102

Boulot, P.; Deschamps, F.; Lefort, G(1990). Pure fetal blood samples obtained by cordocentesis: Technical aspects of 322 cases. Prenat Diagn ,Vol.10,No.5, (May 1990),pp.93 
Brambati, B.; Terzian, E.;Tognoni, G.(1991). Randomized clinical trial of transabdominal versus transcervical chorionic villus sampling methods. Prenat Diagn , vol.11,No.2,(February 1991),pp.285-293.

Brambati, B.; Simoni, G..;Travi, M. (1992).Genetic diagnosis by chorionic villus sampling before 8 gestational weeks: efficiency, reliability, and risks on 317 completed pregnancies. Prenat Diagn, vol.12,No.4,(April 1992),pp.789-799.

Brambati,B.;Tului,L.;Guercilena,S.(2001).Outcome of first trimester CVS for genetic investigation in multiple pregnancy. Ultrasound Obstet Gynecol,vol.17,No.4,(April 2001),pp.714

Brambati,B.;Tului,L.;Camurri,L.(2004). First trimester fetal reduction to a singleton infant or twins:outcome in relation to the final number and karytyping before reduction by CVS, American Journal Obstet Gynecol,vol.191,No.5,(May 2004),pp.2035

Brun,JL.;Mangione,R.;Gangbo,F.(2003). Feasibility,accuracy and safety of chorionic villus sampling:a report of 10741 cases.Prenatal Diagnosis,vol.23,No.4,(April 2003),pp.295301

Bowman, JM. Rh immune disease: Diagnosis, management and prevention. (1991).In:Gynecology and Obstetrics, Sciarra JJ ,Vol 3, Chap 66. Philadelphia, JB Lippincott

Burrows,RF.;Kelton, JG.(1993). Pregnancy in patients with idiopathic thrombocytopenic purpura: Assessing the risks for the infant at delivery. Obstet Gynecol Surv ,vol.48,No.2,(February 1993),pp.781

Caughey, AB.; Hopkins, LM.; Norton, ME.(2006). Chorionic villus sampling compared with amniocentesis and the difference in the rate of pregnancyloss. Obstet Gynecol, vol.108,No.12,(December 2006),pp.612-616

Cederholm,M.;Haglund,B.;Axelsson,O.(2003).Maternal complications following amniocentesis and CVS for prenatal karyotyping. BJOG,vol.110,No.4,(April 2003),pp.392-399

Department of Obstetrics and Gynecology THoAIaSCA, China:Fetal sex prediction by sex chromatin of chorionic villi during early pregnancy. (1975). Chin Med J, Vol.1,pp.117-126

Daffos, F.;Capella-Pavlosky,M.;Forestier,F.(1983). A new procedure for pure fetal blood sampling in utero. Preliminary results at fifty-three cases. American Journal Obstetric Gynecology, vol.146,No.4,(April 1983),pp.985-987

Eddleman, KA.; Malone, FD.; Sullivan, L.; Dukes, K.; Berkowitz,RL.; Kharbutli Y.(2006). Pregnancy loss rates after midtrimester amniocentesis. Obstet Gynecol ,vol.108,No.7, (July 2006),pp.1067-1072

Elias,S.;Emerson,DS.;Simpson,JL.(1994).Ultrasound-guided fetal skin sampling for prenatal diagnosis of genodermatoses. Obstet Gynecol, vo.83,No.4, (April 1994),pp.337-341

Elias,S.;Simpson,JL.(1993).Amniocentesis.In:Essentials of prenatal diagnosis. Simpson, Jl.Churchill Livingstone:New York,pp.27-44

Fergal, D.;Malone, FD.; Jacob,A.; Canick, JA.; Ball, RH.; Nyberg, DA.(2005). First-trimester or second-trimester screening, or both, for Down'ssyndrome. N Engl J Med, Vol.353, No.6, (June 2005), pp.2001-2011

Finegan ,AK.; Sitarenios, G.; Bolan, PL.(1996).Children whose mothers had second trimester amniocentesis: follow-up at school age. Br J Obstet Gynaecol ,Vol.103,No.3, (March 1996),pp.214-218 
Finegan, AK.; Quarrington, BJ.; Hughes, HE.(2000). Child outcome following mid-trimester amniocentesis: Development, behavior and physical status at age 4 years. British Journal Obstetrics Gynaecology , Vol97,No.3-4,( April 2000),pp425-435

Froster ,UG.; Jackson, L.(1996). Limb defects and chorionic villus sampling: results from an international registry, 1992-94. Lancet, vol.347,No.1,(January 1996),pp.489-94.

Ghezzi, .;, Maymon, E.; Redman, M.; Blackwell, S.; Berry, SM.; Romero, R.(2001). Fetal blood sampling.In:Sonography in obstetrics and gynecology: principle and practice, Fleischer AC. pp.775-804, McGraw-Hill; New York

Gratacós, E.; Devlieger, R.; Decaluwé, Wu J.; Nicolini ,U.; Deprest ,JA.(2000). Is the angle of needle insertion influencing the created defect in human fetal membranes? Evaluation of the agreement between specialists' opinions and ex vivo observations. Am J Obstet Gynecol ,vol.182,No.6, (June 2000),pp.646-649

Haberle,J.;Koch,Hg. (2004). Genetic approach to prenatal diagnosis in urea cycle defects. Prenatal Diagnosis,vol.24, No.5,(May 2004),pp.378-383

Hanson ,FW.;Happ, RL.; Tennant, FR.(1990) Ultrasonographically-guided early amniocentesis in singleton pregnancies. Am J Obstet Gynecol , Vol.162,No.9,(October 1990), pp.1376-83.

Horger, EO.;Finch ,H.; Vincent ,VA. (2001).A single physician's experience with four thousand six hundred genetic amniocentesis. Am J Obstet Gynecol, Vol.185, No.11,(November 2001), pp.279-288

Johnson, JM.; Wilson, RD.;Winsor, EJ.;Singer, J.; Dansereau ,J.; Kalousek DK. (1999).The early amniocentesis study: a randomized clinical trial of early amniocentesis versus midtrimester amniocentesis. Fetal Diagn Ther, vo.11,No.4, (April 1996),pp.85-93

Johnson, JM.; Wilson, RD.; Singer, J.;Winsor, E.; Harman, C.;Armson,BA. (1999).Technical factors in early amniocentesis predict adverse outcome. Results of the Canadian early (EA) versus mid-trimester (MA) amniocentesis trial. Prenat Diagn , vol.19,No.6, (June 1999),pp.732-738

Jackson, GL.; Zachary, JM.; Fowler SE.(1992). A randomized comparison of transcervical and transabdominal chorionic villus sampling. N Engl J Med, vol.327,No.5,(May 1992),pp.594-98

Jacobson, B.;Ladfors, L.; Milson, I.(2004). Advanced maternal age and adverse perinatal outcome. Obstet Gynecol, vol.104,No.7,(July 2004), pp.727-733

Kalousek,DK.;Vekemans,M.(2000).Confined placental mosaicism and genetic imprinting: Baillieres Best Practice Results Clin Obstet Gynaecol, vol.14,No.4,(April 2000),pp.723730

Kay,H.;Nelson,M.;Wang Y.(2011).Cordocentesis and fetoscopy.In:The placenta:from development to disease.Kay,H,pp.147, Blackwell publication;ISBN:978-1-4433-3366$4 ; \mathrm{UK}$

Karp, LE.; Hayden, PW.(1977). Fetal puncture during midtrimester amniocentesis. Obstetrics Gynecology ,vol.115,No.12, (December 1977),pp.15-19

Kleinhaus, K.; Perrin, M.; Friedlander, Y.; Paltiel, O.; Malaspina, D.; Harlap, S.(2006). Paternal age and spontaneous abortion. Obstet Gynecol, vol.108,No.2,(February 2006),pp.369-377

Kong, CW.; Leung, TN.; Leung, TY.; Chan, LW.;Sahota, DS.; Fung, TY.(2006). Risk factors for procedure-related fetal losses after mid-trimester genetic amniocentesis. Prenat Diagn ,vol.26,No.6, (June2006), pp.925-930 
Kotzot,D.(2001). Complex and segmental uniparental disomy; review and lessons from rare chromosomal complements. J Med Genet,vol.38,No.8,(August 2001),pp.497-507

Liao, C.; Wei, J.;Li, Q.; Li, L. Li J.; Li, D. (2006). Efficacy and safety of cordocentesis for prenatal diagnosis. Int J Gynecol Obstet, vol.93,no.4, (April 2006),pp.13-17.

Los,Fj.;van den BC.;Wildschut,HI.(2001). The diagnostic performance of cytogenetic investigation in amniotic fluid cells and chorionic villi. Prenatal Diagnosis, vol.21,No.12,(December 2001),1150-1158

Mariona, FG.; Bhatia, R.; Syner, FN.(1986). Chorionic villus sampling changes maternal serum alpha-fetoprotein. Prenat Diagn, vol.6,No.5,(May 1986),pp.69-73

Meier,C.;Huang, T.; Owolabi, T.; Summers, A.;Wyatt PR. The identification of risk of spontaneous fetal loss through second-trimester maternal serum screening. Am J Obstet Gynecol , vol.193,No5-6,(June 2005),pp.395-403

Monni,G.;Ibba,RM.;Lai,R.(1993).Early transabdominal chorionic villus sampling in couples at high genetic risk. Am J Obstet Gynecol, vol.168,No.1,(January 1993),pp.170-171

Medical Research Council working party on amnio-centesis. (1978).An assessment of the hazards of amniocentesis. Br J Obstet Gynaecol, vol.85,No.2,(February 1978),pp.1-41

Muller, F.;Thibaud, D.; Poloce, F.; Gelineau, MC.; Bernard, M.; Brochet, C.(2002). Risk of amniocentesis in women screened with positive for Down syndrome with second trimester maternal serum markers. Prenatal Diagnosis, vol.22,No.11,(November 2002),pp.1036-1039

Milner, AD.; Hoskyns, EW.; Hopkin, IE. (1992).The effects of midtrimester amniocentesis on lung function in the neonatal period. Eur J Pediatr, vol.151,No.3, (March 1992), pp. $458-460$

Millaire, M.; Bujold, E.; Morency, AM.; Gauthier, RJ.(2006). Mid-trimester genetic amniocentesis in twin pregnancy and the risk of fetal loss. J Obstet Gynaecol Can ,vol.28,No.1,(January 2006),pp.512-518

Milunsky,A.(2010).Complications of amniocentesis,In:Genetic disorders and the fetus,Milunsky J,pp1184-1185,Wiley-Blackwell,ISBN 978-1-4051-9087-9;Oxford UK

MRC Working Party: An assessment of the hazard of amniocentesis. British Journal Obstetric Gynecology, vol.85,No.6, (June 1992),pp.1-41

Nadel, A.(2007).Letter to Editor: Pregnancy loss rates after midtrimester amniocentesis. Obstet Gynecol ,vol.109,No.7-8,(July 2007),pp.451

Nicolaides, K.; Brizot, ML.; Patel, F.(1994).Comparison of chorionic villus sampling and amniocentesis for fetal karyotyping at 10-13 weeks' gestation. Lancet ,vol.344,No.3, (March 1994),pp.435-439

Nevo,Y.;Shomrat,R.;Yaron,Y.;Harel,S,Legum,C. (1999). Fetal muscle biopsy as a diagnostic tool in Duchenne muscular dystrophy. Prenatal Diagnosis, vol.19,No.10,(October 1999),pp.921-926

Odibo,AO.;Dicke,JM,Gray,DL.(2008). Evaluate the rate and risk factors for fetal loss after CVS. Obstet Gynecol,vol.112,No.5,(May 2008),pp.813

Papantoniou, NE.; Daskalakis, GJ.; Tziotis, JG.; Kitmirides ,SJ.; Mesogitis, SA.;Antsaklis, AJ.(2001). Risk factors predisposing to fetal loss following a second trimester amniocentesis. BJOG ,vol.108,No.6,(June2001),pp.1053-1056

Paz,A.;Gomen,R.;Pokasman,I.(2001).Candida sepsis following transcervical CVS. Infect Dis Obstet Gynecol.vol.9,No.3,(March 2001),pp.147-148 
Pijpers,L.; Jahoda, MGJ.; Vosters ,RPL.(1988). Genetic amniocentesis in twin pregnancies. $\mathrm{Br}$ J Obstet Gynaecol,vol.95,No.4,(April 1988),pp.323-326

Phipps,S.;Zinn,A.;Opitz,J.;Reynolds,J.(2005).Psychological response to amniocentesis:Effects of coping style.American Journal of medical genetics,vol.25,No.6,(June 2005),pp.143148

Philip,J.;Silver,RK.;Wilson,RD.;Thom,EA.(2004).Late first trimester invasive prenatal diagnosis:results of an international randomized trial. Obstet Gynecol,vol.103, No.6,(June 2004),pp.1164-1173

Phupong,V.;Ultchaswadi,P.(2006).Spontaneus reseal of ruptured membranes after genetic amniocentesis.Journal mediacal association Thai,vol.89,No.7,(July 2006),pp.1033-1035

Pergament ,E.(2000).The application of fluorescence in- situ hybridization to prenatal diagnosis.Current opinion obstet gynecology, vol.72,No.12,(December 2000),pp.41-43

Preis,K.; Ciach,K.,Swiatkowska-Freun,M. (2004). The risk of complications of diagnostic and therapeutic cordocentesis. Ginekol.Pol.vol.75,No.10,(October 2004),pp.765-769

Rhoads,GG.;Jacson,LG.;Scheslleman,SE.(1989). The safety and efficacy of CVS for early prenatal diagnosis of cytogenetic abnormalities. $N$ Engl J Med, Vol.320,No.5,(May 1989),pp.609-612

Reid ,KP.; Gurrin, LC.; Dickinson, JE.; Newnham, JP.; Phillips, JM.(1999). Pregnancy loss rates following second trimester genetic amniocentesis. Aust NZ J Obstet Gynaecol ,vol.39,No.2,(February 1999),pp.281-285

Rujiwetpongstorn, J.; Tongsong, T.; Wanapirak, C.(2005) Feto-maternal hemorrhage after cordocentesis at

Maharaj Nakorn Chiang Mai Hospital. J Med Assoc Thai, vol.88,No.5,(May2005),pp.145-9.

Summers ,AM:, Langlois, S.; Wyatt, P.; Wilson,RD.(2007). Prenatal Screening for Fetal Aneuploidy. Joint SOGC-CCMG Clinical Practice Guideline.J Obstet Gynaecol Can ,Vol.29,No.6,(June 2007),pp.146-161

Sundberg,K.; Smidt-Jensen, S., Philip, J. (1997).Amniocentesis with increased cell yield, obtained by filtration and reinjection of the amniotic fluid. Ultrasound Obstet Gynecol ,vol.1,No.2,(February 1991),pp.91-94

Sawa, R.; Hayashi, Z.; Tanaka, T.(2001). Rapid detection of chromososme aneuploidies by prenatal interphase FISH and its clinical utility in Japan.J apan obstetric gynecology, vol.41,No.2,(February 2001),pp.13-15

Savva, GM.;Morris, JK.; Mutton, DE.; Alberman, E.(2006). Maternal age-specific fetal loss rates in Down syndrome pregnancies. Prenat Diagn, vol.26,No.6,(June 2006),pp.499504

Seeds, JW.(2004). Diagnostic mid trimester amniocentesis: how safe? Am J Obstet Gynecol ,vol.191,No.7,(July 2004),pp.608-616

Swift ,PG.; Driscoll, IB.; Vowles, KD.(1979). Neonatal small bowel obstruction associated with amniocentesis. British Medical Journal ,vol.720,No.2,(February 1979),pp.54-56

Sirirchotiyakul, S.; Piyamongkol, W.; Chanprapaph, P.(2000). Cordocentesis at 16-24 weeks of gestation: experience of 1,320 cases. Prenat Diagn vol.20,No.5,(May 2000),pp.224228

Schreck, L. After early amniocentesis chances of fetal loss and foot deformity rise.(1998). Family planning perspectives, vol.30,No.6,(June 1998),pp.249-251

Smith, L.(2007). Letter to Editor: Pregnancy loss rates after midtrimester amniocentesis. Obstet Gynecol , vol.109,No.7,(July 2007),pp.452 
Smidt-Jensen, S.; Permin, M.; Philip, J.(1992). Randomised comparison of amniocentesis and transabdominal and transcervical chorionic villus sampling. Lancet, vol.340,No.4,(April 1992),pp.1237-1244

Sunberg, K.; Bang, J.; Smidt-Jensens, S.; Brocks ,V.(1997). Randomised study of risk of fetal loss related to early amniocentesis versus CVS. Lancet,vol.350,No.11,(November 1997),pp.697-703

Shulman, LP.; Elias, S.; Phillips, OP. (1994). Amniocentesis performed at 14 weeks' gestation or earlier: comparison

with first-trimester transabdominal chorionic villus sampling. Obstet Gynecol ,vol.83,No.9,(September 1994),pp.543-548.

Shah, DM.;Roussis, P.; Ulm, J. (1990). Cordocentesis for rapid karyotyping. Am J Obstet Gynecol , vol.162,No.6,(June 1990),pp. 1548

Sepulveda, W.; Donaldson, A.; Johnson ,RD.(1995). Are routine a-fetoprotein and acetylcholinesterase determinations still necessary at second-trimester amniocentesis? Impact of high-resolution ultrasonography. Obstet Gynecol, vol.85, No.1,(January 1995),pp.107-112

Tepperberg, J.;Pettenati ,MJ.; Rao, PN.(2001).Prenatal diagnosis using interphase fluorescence in situ hybridization (FISH):2-year multi-center retrospective study and review of the literature. Prenatal diagnosis,vol.21,No.6,(June 2001)pp.293

Tabor, A.; Philip, J.; Madsen, M.(1986). Randomise controlled trial of genetic amniocentesis in 4606 low-risk women. Lancet, vol.1,No,5,(May 1986),pp.86-88

Tabor ,A.;Jerne, D.; Bock, JE.(1987). Incidence of rhesus immunization after genetic amniocentesis. British Medical Journal,vol.293,No.3,(March 1987),pp.533-536

Toth-Pal, E.; Papp, C.;Beke, A.; Ban, Z.; Papp, Z.(2004). Genetic amniocentesis in multiple pregnancy. Fetal Diagnosis and Therapy, vo.19,No.6,(June 2004),pp.138-144

Tongsong ,T.; Wanapirak, C.; Kunavikatikul, C.; Sirirchotiyakul, S.; Piyamongkol, W.; Chanprapaph ,P. (2001).Fetal loss rate associated with cordocentesis at midgestation. Am J Obstet Gynecol , vol. 184, no.1, (January 2001),pp.719-723

Thompson, PJ.; Greenough, A.; Nicolaides, KH.(1992). Lung volume measured by functional residual capacity in infants following first trimester amniocentesis or chorionic villus sampling. British Journal of Obsterics and Gynecology , vol.99,No.7-8,( August 1992),479-482

The NICHD National Registry for Amniocentesis Study Group.(1976). Midtrimester amniocentesis for prenatal diagnosis. Safety and accurancy. JAMA ,vol.5, (May1976),pp.1471-1476.

The Canadian Early and Mid-trimester Amniocentesis Trial (CEMAT) Group. (1998).Randomised trial to assess safety and fetal outcome of early and midtrimester amniocentesis. Lancet, vol.351,No.7,(July 1998),pp.242-247

Troyano,JM.;Clavijo,MT.;Clemente,I.;Marco,QY.;Rayward,J.;Mahtani,VG. (2002). Kidney and urinary tract diseases: Ultrasound and biochemical markers. The ultrasound Review of Obstetrics and Gynecology,Vol.2,No.2,(February 2002),pp.92-109

Vaughan,J.;Rodeck,C.Interventional procedures.In:Ultrasound in obstetrics and gynaecology,Dewbury,KC,Meire,HB.pp.557-606.London:Churchill Livingstone, 2001

Valente, P.; Sever, JL.(1994). In utero diagnosis of congenital infections by direct fetal sampling. Isr J Med Sci ,vol.30, No.10,(October1994),pp.414 
Von Dadelszen,P.;Sermer,M.; Hillier,J.(2005).A randomized controlled trial of biopsy forceps and cannula aspiration for transcervical chorionic villus sampling. Br J Obstet Gynaecol, vol.112,No.5,(May 2005),pp.559-566

Wapner, RL.; Johnson, A.; Davis, G.; Urban, A.; Morgan, P.; Jackson, L.(1993). Prenatal diagnosis in twin gestations: a comparison between second-trimester amniocentesis and first-trimester chorionic villus sampling. Obstet Gynecol, vol.82,No.1-2, (February 1993),pp.49

Wilson, RD.(2005) Amended Canadian Guideline for prenatal diagnosis (2005) change to 2005 - techniques for prenatal diagnosis. SOGC Clinical Practice Guidelines.Journal of Obstetrics and Gynecology Canada , vol.27,No. 11, (November 2005). pp.1048-1054

Weiner, S. (1991).Indications, complications ,safety,reliability, and assessment of quality of fetal blood.Ultrasound Obstet Gynecol, vol.1,No.5,(May 1991),pp.17

Welch, RA.; Soha-Salem, EM.;Wiktor, BS.; Van Dyke, DL.; Blessed, WB.(2006). Operator experience and sample quality in genetic amniocentesis. American Journal of obstetrics and gynecology, vol.194,No.12,(December 2006),pp.189-191

Wilson, RD. (2007).Letter to Editor: Pregnancy loss rates after midtrimester amniocentesis. Obstet Gynecol ,vol.109,No.1,(January 2007),pp.451-452

Wurster,KG.;Roemer,VM.;Decker,K.;Hirsch,HA.(1982).Amniotic infection syndrome after amniocentesis.Geburtshilfe Frauenheilkd.vol.42,No.9,(September 1982),pp.676-679

Yukobowich, E,.;Anteby ,EY,.;Cohen, SM.; Lavy, Y.;Granat, M.; Yagel, S.(2001). Risk of fetal loss in twin pregnancies undergoing second trimester amniocentesis. Obstet Gynecol, vol.98,No.11,(November 2001),pp.231-234 


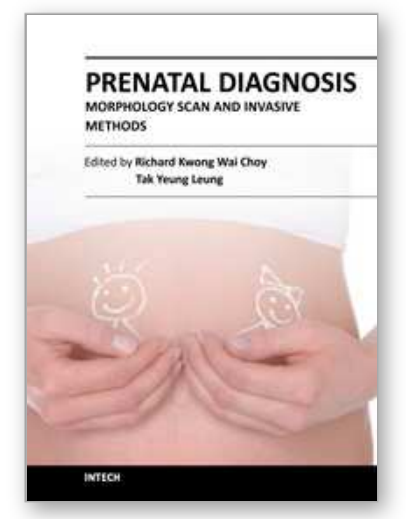

\author{
Prenatal Diagnosis - Morphology Scan and Invasive Methods \\ Edited by Dr. Richard Choy
}

ISBN 978-953-51-0614-2

Hard cover, 210 pages

Publisher InTech

Published online 29, June, 2012

Published in print edition June, 2012

This book provides detailed and comprehensive coverage on various aspects of prenatal diagnosis-with particular emphasis on sonographic and molecular diagnostic issues. It features sections dedicated to fundamentals of clinical, ultrasound and genetics diagnosis of human diseases, as well as current and future health strategies related to prenatal diagnosis. This book highlights the importance of utilizing fetal ultrasound/clinical/genetics knowledge to promote and achieve optimal health in fetal medicine. It will be a very useful resource to practitioners and scientists in fetal medicine.

\title{
How to reference
}

In order to correctly reference this scholarly work, feel free to copy and paste the following:

Sonja Pop-Trajković, Vladimir Antić and Vesna Kopitović (2012). Invasive Prenatal Diagnosis, Prenatal Diagnosis - Morphology Scan and Invasive Methods, Dr. Richard Choy (Ed.), ISBN: 978-953-51-0614-2, InTech, Available from: http://www.intechopen.com/books/prenatal-diagnosis-morphology-scan-and-invasivemethods/invasive-prenatal-diagnosis

\section{INTECH}

open science | open minds

\section{InTech Europe}

University Campus STeP Ri

Slavka Krautzeka 83/A

51000 Rijeka, Croatia

Phone: +385 (51) 770447

Fax: +385 (51) 686166

www.intechopen.com

\section{InTech China}

Unit 405, Office Block, Hotel Equatorial Shanghai

No.65, Yan An Road (West), Shanghai, 200040, China

中国上海市延安西路 65 号上海国际贵都大饭店办公楼 405 单元

Phone: +86-21-62489820

Fax: +86-21-62489821 
(C) 2012 The Author(s). Licensee IntechOpen. This is an open access article distributed under the terms of the Creative Commons Attribution 3.0 License, which permits unrestricted use, distribution, and reproduction in any medium, provided the original work is properly cited. 